\title{
Assessment of Human-Wildlife Conflict and the Attitude of Local Communities to Wild Animal Conservation around Borena Sayint National Park, Ethiopia
}

\author{
Salahadin Merkebu' and Dereje Yazezew ${ }^{1}{ }^{2}$ \\ ${ }^{1}$ Department of Biology, Mekaneselam High School, South Wollo, Amhara, Ethiopia \\ ${ }^{2}$ Department of Biology, College of Natural and Computational Sciences, Debre Berhan University, P.O. Box 445, \\ Debre Berhan, Ethiopia
}

Correspondence should be addressed to Dereje Yazezew; deredbu2003@gmail.com

Received 15 November 2020; Revised 16 March 2021; Accepted 31 March 2021; Published 9 April 2021

Academic Editor: Daniel I. Rubenstein

Copyright ( 92021 Salahadin Merkebu and Dereje Yazezew. This is an open access article distributed under the Creative Commons Attribution License, which permits unrestricted use, distribution, and reproduction in any medium, provided the original work is properly cited.

\begin{abstract}
Human-wildlife conflict (HWC) has increased globally because of an increase in the human population, particularly in developing countries. This study was conducted to investigate the status of HWC and the attitude of local communities to wildlife conservation around Borena Sayint National Park, Northeastern Ethiopia. Data were collected between September 2017 and May 2018 using a face-to-face questionnaire survey (230), focus group discussions (7), and direct observation on the crop foraging. The data were analyzed using descriptive statistics, and the responses were compared using a nonparametric Pearson chi-square test. The majority of respondents (70\%) reported the existence of HWC manifested because of the damage received to their assets (both crop and livestock). Canis aureus, Panthera pardus, Crocuta crocuta, and Papio hamadryas were stated as livestock depredators. Gelada, rabbit, porcupine, klipspringer, bushbuck, and duiker were considered as the major crop raiders. Over half (57.83\%) of the respondents had a positive attitude, while others (36.09\%) had a negative attitude towards the conservation of wildlife due to frequently faced problems. Respondents in different villages differed significantly $(\chi 2=27.385, \mathrm{DF}=12, P<0.05)$ in their attitude towards wildlife. Possible mitigation actions need to be undertaken to reduce the wildlife damage such that wildlife can sustainably be managed in the park.
\end{abstract}

\section{Introduction}

HWC has been identified as one of the main threats to the continued survival of many wildlife species in different parts of the world [1]. In addition, it has become a significant threat to both the wildlife and local human populations. Currently, human beings are insensitive to the value of wildlife in developing countries where HWC is more intensive, and rural people largely depend on livestock holdings and agriculture for their livelihoods and income generation $[2,3]$. The growing human population and the resultant overlap of the same needs with established wildlife territories have been one of the major causes of HWC [3]. It is becoming more frequent and more severe due to human population growth and their activities [4]. This conflict, on the other hand, creates fear in the mind of people particularly when it is with large mammals such as lion (Panthera leo), hyena (Crocuta crocuta), leopard (Panthera pardus), and elephant (Loxodonta africana).

Crop damage, livestock depredation, and attacks to humans are the main problems around national parks $[5,6]$. Geladas (Theropithecus gelada), vervet monkeys (Chlorocebus pygerythrus), rodents, and bird species are to be among the destructive wild animals in terms of crop damage [2]. Cattle are the most affected livestock, and leopard is the most common livestock depredator, followed by hyena (Crocuta crocuta) and African rock python (Python sebae) [7]. Thus, farmers consider these animals as pest as the animals constitute a severe problem for the farmers adjacent to national parks [8]. 
As fragmentation of land increases, animals come in direct conflict with people [3]. The conflict brings negative effects to wild animals, damage to property such as crop damage, loss of human life, and injuries to people and wildlife [1]. Most deaths of animals occurred outside reserve borders caused by legal and illegal hunting as well as road accidents and accidental snaring [9].

In Ethiopia, many protected areas faced significant challenges in meeting human and wildlife needs [10]. Like other national parks, Borena Saynt National Park (BSNP) has been facing a number of threats due to increasing human population and livestock pressure through heavy grazing. Moreover, land degradation, shortage of animal forage and grazing land, low fertility of the soil, scarcity of cultivable land, and absence of farm activities are among the critical socioeconomic problems of the local community that pose pressure on the park [11]. Therefore, the aim of the present study was to investigate the extent of economic losses to human caused by wildlife and the attitude of local farmers to the animals in and around Borena Saynt National Park (BSNP).

\section{Materials and Methods}

2.1. Description of the Study Area. Borena Saynt National Park (BSNP) was established in 2009 by the Amhara National Regional State with regulation number 68/2009. The study area is located in the South Wollo Zone of the Amhara National Regional State in Northeastern Ethiopia (Figure 1). It lies between 50 ' $45.4^{\prime}$ to $53^{\prime}$ '58.3' $\mathrm{N}$ latitude and 40 ' $28.4^{\prime}$ ' to 54 ' 49' E longitude with an approximate area of 15,262 hectares [12]. It lies in the woredas of Borena to the south, Saynt to the north and Mehal Saynt to the east. The largest portion of the park is found in Borena woreda [13].

BSNP extends between 2188 and 3732 meters asl., forming parts of the upper watershed of the Abbay River [14]. The rainfall of the area is bimodal with a mean annual rainfall of $1115 \mathrm{~mm}$ and a mean annual temperature of $17.1^{\circ} \mathrm{C}$. The park is heterogeneous in vegetation type and classified into two vegetation zones, which occur below and above 3000 meters [14]. Out of the total 30 mammalian species recorded in the park, Ethiopian wolf (Canis simensis), Gelada baboon (Theropithecus gelada), Stark's hare (Lepus strackii), and Menelik's bushbuck (Tragelaphus scriptus meneliki) are endemic [11, 13].

2.2. Study Design and Site Selection. A preliminary survey was conducted during mid-September 2017 to identify the boundaries and decide the number of villages and to have a general understanding of the overall situations of the park. In order to assess the resource sharing conflict between human and wildlife, semistructured questionnaires were interviewed to the farmers. The questionnaires were pretested among some groups of the respondents, which did not include the main sample group. Seven villages were selected based on the distance from the park and problems related to crop damage and livestock loss. These villages were Kelecha, Serti, Yenat, Sekdre, Sako, Feta-woju, and Libanos, ranging from $0 \mathrm{~km}$ to $4 \mathrm{~km}$ from the park. Two hundred thirty (230) households randomly selected from these seven villages. The total population of households' sample frame was established by collecting a complete landholders' list record from each Kebele administration office. Based on Cochran (1977) population correction factor, 230-sample household was selected using a simple random sampling technique from the total population of 1954 households.

2.3. Method of Data Collection. Data collection was conducted between September 2017 and May 2018. Semistructured questionnaires were designed mainly to check whether there is a human-wildlife conflict or not around BSNP. Data concerning the status of human-wildlife conflict, the extent of crop damage and livestock depredation, the general socioeconomic status of the community, and attitude of local people to wildlife were collected from the participant households. The questionnaires were administered to farmers within their farming area or residence by the researcher and field assistants [15]. The questionnaires included both open- and close-ended questions to get information about HWC interactions in the area.

To observe the extent of crop damage by wildlife and to compare the result with the response given by the local people, five sites were randomly selected. For each site, five corresponding cultivated land covering an area of $30,000 \mathrm{~m}^{2}$ were selected randomly. Each cultivated lands was divided into five grids, where each grid has an area of $6,000 \mathrm{~m}^{2}$ as used by Yihune [16]. For each grid, the type of crop grown, condition of the crop before damage, area of damaged portion, part of plant eaten, and crop species eaten were recorded [17]. Each grid was visited three times a week from September to December 2017 to count the crop damage and to identify the types of animals that caused the damage. Two focus group discussions in each study site were conducted after questionnaire interviews to supplement the questionnaire data. The group sizes in each discussion site vary from 4 to 10 people.

2.4. Data Analysis. Statistical Package for the Social Sciences (SPSS) version 20 was used to make the data analysis. Descriptive statistics and Pearson chi-square test were used for the analysis of the collected data. Pearson chi-square test was used to determine the significant difference of villages in ways of protecting crop damage, trends in crop damage, local people's attitude towards wildlife, and types of conflict they faced by wild animals. Chi-square test at $P<0.05$ (2tailed) was considered significant. The information was collected from group discussion summarized by text analysis and presented in a narrative way.

\section{Results}

Out of 230 respondents of household survey, 121 were male and 109 were female. Regarding educational level, most (142) were literate, and the rest (88) were uneducated. In terms of age, $32.17 \%$ and $33.48 \%$ of respondents in the study area were in the age groups of 30-39 and 40-49, respectively. 


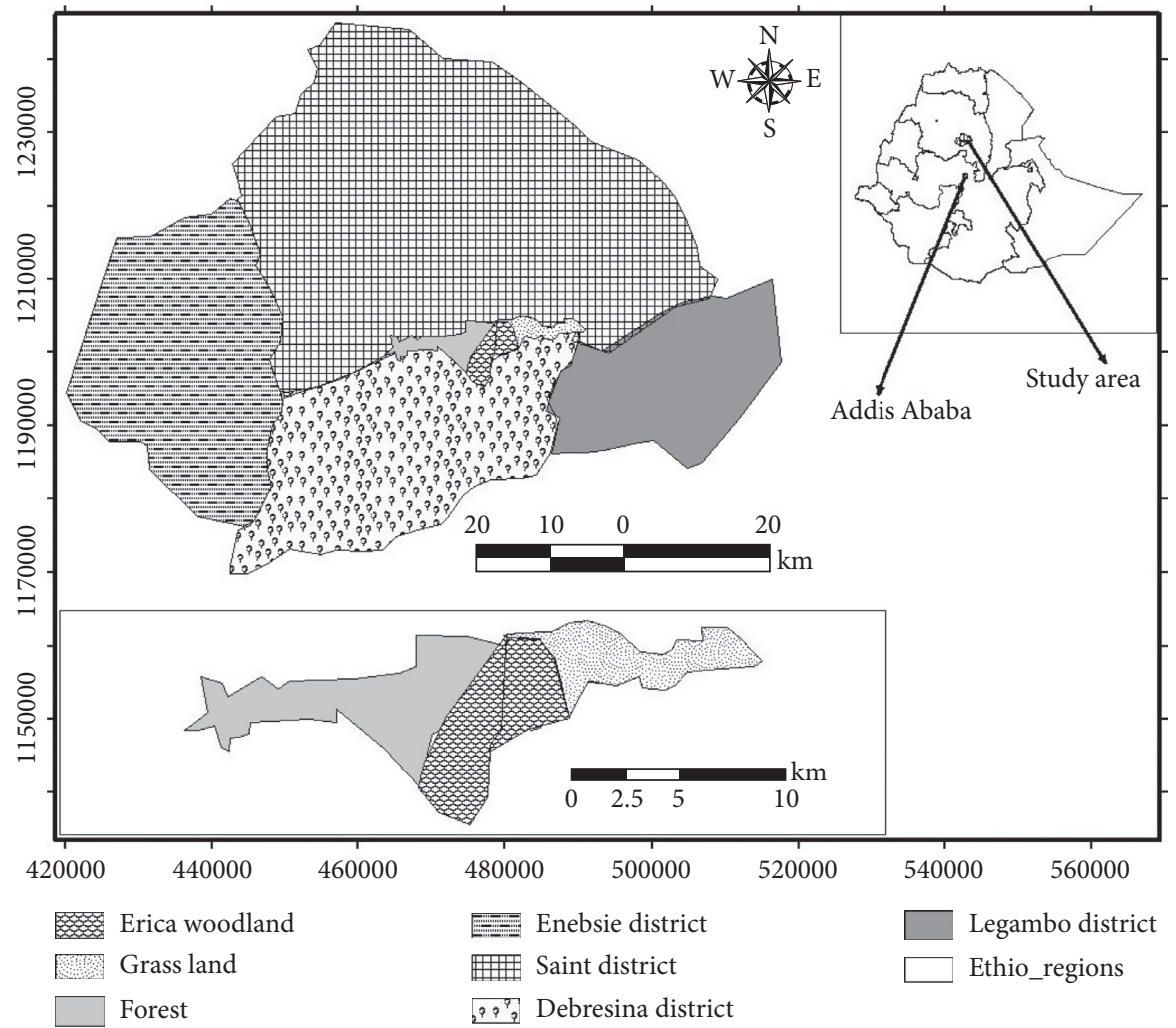

Figure 1: Map of BSNP and its bordering districts [12].

Relatively few (15.22\%) of respondents were equal to or older than 50 years of age. In general, more than $65 \%$ of respondents in the study area were in the age groups of 30-49. The main social economic activities of the respondents were mixed farming and livestock keeping. Few of respondents depend on other income source such as minibusiness, honey collection from traditional beekeeping, guarding the park, and income from sales of local handcrafts. The respondents are highly dependent on the park for grazing land, firewood, fencing and construction service, fodder for their livestock, and sale.

Among the respondents, 70\% reported that there were both problems of crop damage and livestock depredation by wild animals. However, $17 \%$ of them reported that they faced only livestock depredation by wild animals and $7.8 \%$ of them reported that crop was damaged by wild animals. The remaining $5.2 \%$ of the respondents reported that they did not face any damages caused by wild animals (Table 1). The response of respondents from each village was significantly differed in the types of damages they faced by wild animals in the study area $\left(x^{2}=1.197, \mathrm{df}=18, P<0.05\right)$.

The result showed that all surveyed villages of respondents reared about 3529 livestock (sheep, goat, cattle, donkey, and horse). Of the livestock's owned, sheep and goat largely depredated by wild carnivores followed by cattle and donkey. From all surveyed villages, about 233 of sheep, goat, cattle, donkey, and horse depredated within the last five years (Table 2). Out of the total kill caused by wild carnivores in the last five years, about $11.26 \%$ were on sheep, $8.06 \%$ were on goat, and $3.79 \%$ were on horse. Golden jackal (Canis aureus) was mentioned as the most problematic wild carnivore followed by leopard (Panthera pardus), spotted hyena (Crocuta crocuta), and Hamadryas baboon (Papio hamadryas). From the total predated livestock 71 and 68 livestock were killed by golden jackal and leopard, respectively, in the last five years. Spotted hyena and hamadryas baboon also contributed to 54 and 40 of killed livestock (Table 3). The annual kill of livestock was about 47 , and, on the average, the annual monetary loss was 26,580 ETB (948.4 USD) in the study area. In general, the economic loss due to depredations caused by these four wild carnivores in the last five years on sheep, goat, cattle, donkey, and horse accounted to 132,900 ETB (1173.9 USD).

According to respondents, high livestock losses by wild animals were recorded in the closest villages $(<1 \mathrm{~km})$ such as Sekdre, Sako, and Yenat, and the least livestock predations were recorded in Fetta-woju and Libanos, farthest villages $(2-4 \mathrm{~km})$. The response of respondents in Table 3 revealed that there was strong conflict between local farmers and these wild carnivores.

Animal species responsible for damaging crops were geladas (Theropithicus gelada), hamadryas baboon (P. hamadryas), Menelik's bushbuck (Tragelapus scrpitus), bush duiker (Sylvicapra grimmia), klipspringer (Oreotragus oreotlagus), rabbit (Lepus starcki), and porcupine (Hystrix cristata) (Table 4). All of them damaged crop during the daytime. However, some of them like porcupine and Menelik's bushbuck damaged crop at night (nocturnal). Geladas, hamadryas baboon, and Menelik's bushbuck caused damage mainly by trampling and feeding activities, 
TABLe 1: Percentages of respondents with regard to types of problems faced by wildlife.

\begin{tabular}{|c|c|c|c|c|c|}
\hline \multirow[b]{2}{*}{ Villages } & \multirow[b]{2}{*}{$N$} & \multicolumn{4}{|c|}{ Types of problem faced by wildlife } \\
\hline & & Crop damage only (\%) & Livestock depredation only (\%) & Both livestock and crop damage (\%) & Not at all (\%) \\
\hline Kelecha & 33 & 0.0 & 12.1 & 87.9 & 0.0 \\
\hline Seriti & 28 & 7.1 & 14.3 & 71.4 & 7.1 \\
\hline Yenat & 41 & 2.4 & 17.1 & 80.5 & 0.0 \\
\hline Sekdre & 32 & 0.0 & 0.0 & 100.0 & 0.0 \\
\hline Sako & 37 & 13.5 & 18.9 & 67.6 & 0.0 \\
\hline Fetta-woju & 30 & 20.0 & 46.7 & 0.0 & 33.3 \\
\hline Libanos & 29 & 13.8 & 10.3 & 75.9 & 0.0 \\
\hline Total & 230 & 7.8 & 17.0 & 70.0 & 5.2 \\
\hline
\end{tabular}

TABLE 2: Livestock depredation by wild carnivores in a period of five years (June 2013-May 2018).

\begin{tabular}{lccc}
\hline Types of livestock & Livestock number & Predated livestock & \% of predated livestock \\
\hline Sheep (Ovis aries) & 1110 & 125 & 11.26 \\
Goat (Capra aegagrus) & 844 & 68 & 8.06 \\
Cattle (Bos taurus) & 989 & 24 & 2.43 \\
Donkey (Equus asinus) & 454 & 11 & 2.42 \\
Horse (Equus caballus) & 132 & 5 & 3.79 \\
Total & 3529 & 233 & 27.96 \\
\hline
\end{tabular}

TABLE 3: Livestock lost by depredation in five years period.

\begin{tabular}{|c|c|c|c|c|c|c|}
\hline \multirow{2}{*}{ Villages } & \multirow[b]{2}{*}{$N$} & \multicolumn{5}{|c|}{ Livestock lost by predators } \\
\hline & & No. of livestock & Golden jackal & Leopard & Spotted hyena & Hamadryas baboon \\
\hline Kelecha & 33 & 506 & 6 & 18 & 3 & 2 \\
\hline Seriti & 28 & 414 & 13 & 6 & 9 & 4 \\
\hline Yenat & 41 & 592 & 19 & 12 & 9 & 4 \\
\hline Sekdre & 32 & 484 & 11 & 17 & 13 & 11 \\
\hline Sako & 37 & 533 & 8 & 14 & 11 & 18 \\
\hline Fetta-woju & 30 & 508 & 7 & 0 & 4 & 0 \\
\hline Libanos & 29 & 492 & 7 & 1 & 5 & 1 \\
\hline Total & 230 & 3529 & 71 & 68 & 54 & 40 \\
\hline
\end{tabular}

TABLE 4: Rank of wild animals based on the extent of damage cost on crops.

\begin{tabular}{lcc}
\hline Wild animals & No. of respondents & Rank based on damage they cause \\
\hline Gelada baboon & 230 & 1 \\
Hamadryas baboon & 221 & 2 \\
Rabbit & 212 & 3 \\
Bushbuck & 198 & 4 \\
Porcupine & 154 & 5 \\
Klipspringer & 103 & 6 \\
Bush duiker & 78 & 7 \\
\hline
\end{tabular}

while the damage by rabbit, porcupine, klipspringer, and bush duiker was mainly feeding. Geladas, rabbit, and hamadryas baboon caused damage on crops in all stages from the time of germination to the time of harvest, whereas Menelik's bushbuck, bush duiker, and klipspringer affected crop early in the seedling. Root portions and grain of wheat and potato tubers were eaten by porcupine.

A varieties of crop raiders mainly caused damage on wheat (Triticum aestivum), potato (Solanum tuberosum), and barley (Hordeum vulgare) in the study area because these food crops were the most common cultivated crops in the study area. The respondents also reported that maize
(Zea mays), lentil (Lens culinaris), and other food crops were the least vulnerable to crop raiders. Based on direct observation, the estimated yield loss of the three cultivated crops, namely wheat, barley, and potato due to crop raiders was about $2743 \mathrm{~kg}$. The loss covered $7.57 \%$ of the total annual production of the total sampled area of the three crops. In monitory term, the overall loss to farmers in the study sites estimated to be 21,644 ETB (772.3 USD) per sampled site $\left(150,000 \mathrm{~m}^{2}\right)$.

Based on the response of respondents, the occurrence and frequency of crop raiding is dependent on a multitude of condition such as level of human activities on the farm and 
cultivated crops with respect to the park location. Out of 230 household respondents, $84.3 \%$ reported as the trend is increasing from time-to-time. However, $8.3 \%$ of them said it is decreasing, and the rest $7.4 \%$ reported that there is no idea about the trend of crop raiding. The trend in crop damage by wild animals among villages differed significantly $(\chi 2=95.745, \mathrm{df}=12, P<0.05)$. Respondents that live close to the park area faced highest crop damage than those living $2 \mathrm{~km}$ away from the national park (Table 5).

Out of the different traditional techniques used by local communities against crop raiding, guarding (eye watching), fencing, chasing, strange scents, and trapping are the most common (Figure 2). There was a significant difference $\left(x^{2}=44.035, \mathrm{df}=30, P=0.05\right)$ among villages with respect to the techniques used in protecting crop damage. However, guarding is the most intensively used and effective method in all villages around BSNP.

Of the total respondents, more than half (57.8\%) of them had positive attitude towards wildlife found in the study area. In contrast, $36.1 \%$ of the respondents had negative attitude towards wildlife. The remaining $6.1 \%$ of the respondents had neither positive nor negative attitude towards wildlife (Table 6). Majority of respondents from villages distant from the park, such as Sekdre (71.9\%) and Fetta-woju (70\%) had positive attitude towards wildlife, while respondents closest to the park (Sako $=54.1 \%$ and Seriti $=50 \%$ ) had negative view towards wildlife. There was significant difference in the attitude towards wildlife among respondents in different villages $(\chi 2=27.385, \mathrm{df}=12$, $P<0.05)$.

The reasons stated for positive attitudes of respondents towards wildlife were maintenance of ecosystem balance, source of income to the local people, enjoyment derived from viewing wildlife, and ethical values. On the contrary, reasons given for the negative views towards wildlife across the study sites were problems in crop damage, livestock depredation, and threat to human lives.

Over half (51.3\%) of the respondents reported that the number of wildlife has been declined over the past five years, whereas $43.0 \%$ of respondents said that the number of wildlife populations in the park increased over the five years duration (Table 7).

\section{Discussion}

In the study area, respondents had large family size with small landholdings that will increase the demand for more resources to fulfill the basic need for their family livelihood. Such intense stress restricted the normal activities of wild animals. The result is similar to the finding of Yihune [16] who reported that a high number of the human population has its own impact on the wildlife population. Illegal uses of the park grass to feed their livestock and other purpose caused a scarcity of grass for herbivores and disturbed the natural behavior of wildlife in the park that exacerbate the conflict as reported by Andarge [18]. Agriculture expansion, firewood collection, and cutting trees for the different purposes were the most crucial threats to the study area that directly affect the wildlife population. This result was in agreement with Berihun et al. [4] who reported that local people make extensive use of easily accessible areas of forest resources to satisfy their needs as firewood, charcoal, and construction material in Kafta Sheraro National Park. Those anthropogenic impacts on the park were major factors affecting the distribution of wildlife population in their natural habitats $[19,20]$.

The long-term success of conservation efforts required to know local communities' attitudes towards wildlife [10]. According to questionnaire surveys and local community information, $57.8 \%$ of respondents had a positive attitude towards the conservation of wildlife due to its value to maintaining ecosystem balance, source of income to the local people, enjoyment derived from viewing wildlife, and ethical values. This is in line with the finding of Girmay and Teshome [2].

HWC is an increasing concern in all parts of the world particularly in developing nations where people depend on agriculture [7]. Wild animals found around the study area potentially caused economic loss especially in villages such as Yenat, Sekdre, Seriti, and Sako. The possible reason for the differences in economic losses among villages is the closeness of these affected villages $(<1 \mathrm{~km})$ to the park than others distant from the park $(2-4 \mathrm{~km})$. According to Acha and Temesgen [5], the level of conflict varied among survey villages. Loss of livestock, crop damage, and other problems are the main reported causes for HWC in different parts of Africa [1]. Among the respondents, 70\% reported that there were both problem of crop damage and livestock depredation by wild animals. A similar finding has been reported by Girmay and Teshome [2]. Mojo et al. [21] also explained that more than $90 \%$ of the households faced damages to their property by wild animals and significantly contributed to the shortage of food and poverty.

Leopard, spotted hyena, hamadryas baboon, and golden jackal were the common wild carnivores, which came out from the park in the study area and attacked domestic animals. This result was in agreement with Girmay and Teshome [2]. Sheep, goats, cattle, donkeys, and horses were types of domestic animals killed by the four wild carnivores in BSNP. Likewise, a survey conducted in Senkele Swayne's Hartebeest Sanctuary showed livestock loss such as goat, sheep, cattle, and donkey by wild carnivores [22]. Respondents stated that spotted hyena preyed on all types of livestock, but leopard and golden jackal preyed on sheep and goat [23]. Golden jackal mentioned as the most problematic wild carnivore followed by leopard, spotted hyena, and hamadryas baboon. Studies in Choke Mountain and Semien Mountain National Park reported that human conflict with golden jackals was very serious compared to other wild carnivores [7, 16]. High livestock lost by wild animals recorded in Sekdre, Sako, and Yenat villages, which are very close to the park. According to Acha and Temesgen [5] and Nibret et al. [7], the level of conflict is depending on the distance from protected area.

In addition to the direct impacts such as injury and fatality, crop and livestock loss, wildlife stances hidden impacts to the local community such as opportunity costs, transaction costs, and health impacts. Thus, the potential 
TABLe 5: Approximate distance from the park and trend in crop damage by crop raiders in the last five years.

\begin{tabular}{|c|c|c|c|c|}
\hline \multirow{2}{*}{ Villages } & \multirow{2}{*}{ Distance from the park $(\mathrm{km})$} & \multicolumn{3}{|c|}{ Trend of crop damage compared to the last five years } \\
\hline & & Increasing $(\%)$ & Decreasing (\%) & No idea \\
\hline Kelecha & $1-2$ & 93.9 & 6.1 & $0.0 \%$ \\
\hline Seriti & $1-2$ & 92.9 & 7.1 & $0.0 \%$ \\
\hline Yenat & $0-1$ & 100.0 & 0.0 & $0.0 \%$ \\
\hline Sekdre & $0-1$ & 100.0 & 0.0 & $0.0 \%$ \\
\hline Sako & $0-1$ & 100.0 & 0.0 & $0.0 \%$ \\
\hline Fetta-woju & $3-4$ & 40.0 & 30.0 & $30.0 \%$ \\
\hline Libanos & $2-3$ & 51.7 & 20.7 & $27.6 \%$ \\
\hline Total & & 84.3 & 8.3 & $7.4 \%$ \\
\hline
\end{tabular}

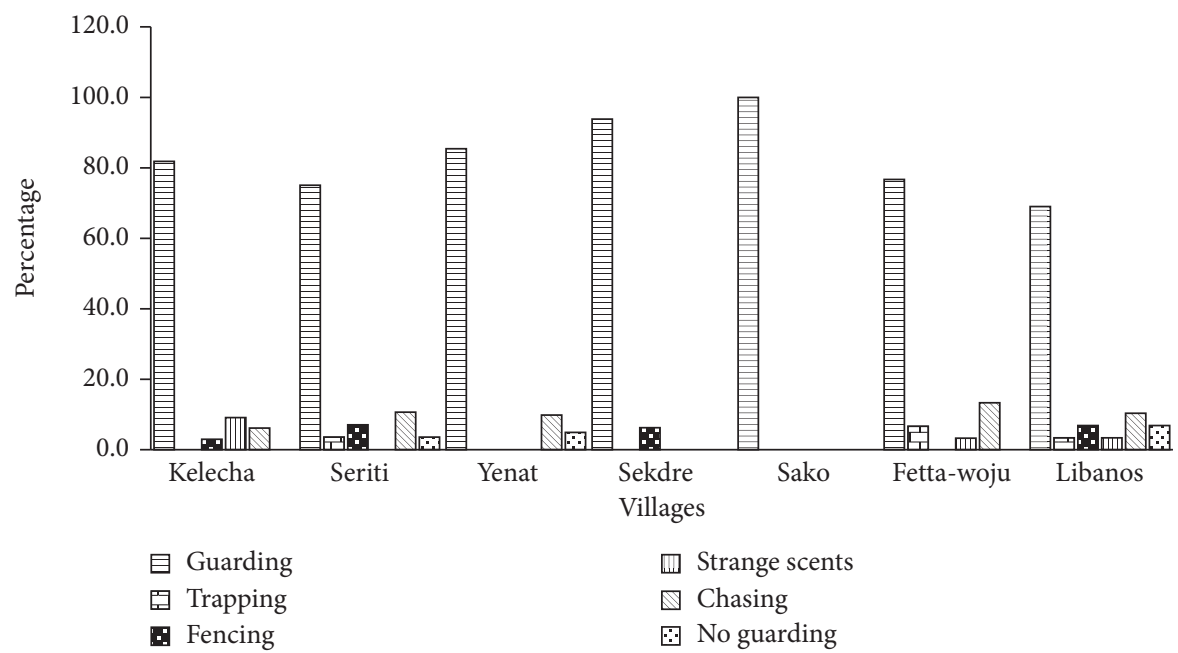

FIGURE 2: Different types of traditional techniques used by respondents in different villages around BSNP.

underlining mechanisms that trigger human responses are dependent on resources and perception of risks based on the nature of the interaction with the animals [24]. These threats of humans and damages to resources need to be reduced by developing resources protection measures, accurate and rapid verification of damages, and compensation schemes as a mitigation strategy to economic impacts $[24,25]$.

Wild mammal species such as gelada baboon, hamadryas baboon, rabbit, bushbuck, porcupine, bush duiker, and klipspringer reported to raid crops and caused economic loss to farmers around the study area. A similar study in Gendo Guratirigni forest showed that wild animals often destroyed crops and caused economic loss to farmers [26]. Gelada baboon was the most commonly reported crop raider on the farmland causing much damage and rank first $[27,28]$. This means that the frequency of crop damage by gelada is high in farmland areas near the cliff as compared to other crop raiders [18]. Research conducted by Girmay and Teshome [2] showed that wild animals raided crops such as wheat (Triticum aestivum), maize (Zea mays), bean (Phaseolus vulgaris), and barley (Hordeum vulgare), which was similar to the present finding. These animals thought to be a threat to human safety are less tolerated than less threatening ones [28].
Respondents that live close to the park area (Yenat, Sekdre, Seriti and Sako) faced highest crop damage than those living $2 \mathrm{~km}$ far away from the park area (Libanos and Fetta-woju). This result is in line with the study of Datiko and Bekele [29] who reported that those communities who live near the park faced frequent crop damage. The negative attitude of communities to wild animals has a direct relationship to the economic loss caused by the animals. Local farmers utilized a number of traditional control measures against crop raiders but guarding (eye watching) was the most familiar and effective tool. Respondents argued that crop guarding mainly undertook throughout crop growing season, which becomes intensified during the harvesting season [26]. According to respondents, children carried out nearly half $(49.13 \%)$ of guarding tasks and $30 \%$ carried out by women and the remaining $20.87 \%$ carried out by men. This response indicated that local people especially children spent most of their time and efforts at their farms guarding crops. This result was in agreement with the finding of Girmay and Teshome [2] who reported that local people guard their crop from the beginning to the end by one person mainly the child to protect the crop permanently. This could have indirect impacts on children's reduced school attendance or absenteeism [30] (Figure 3). 
TABle 6: Attitudes of the respondents towards wildlife conservation.

\begin{tabular}{|c|c|c|c|c|}
\hline \multirow{2}{*}{ Villages } & \multirow{2}{*}{$N$} & \multicolumn{3}{|c|}{ Respondents attitude towards wildlife } \\
\hline & & Positive (\%) & Negative (\%) & Neutral (\%) \\
\hline Kelecha & 33 & 54.5 & 39.4 & 6.1 \\
\hline Seriti & 28 & 42.9 & 50.0 & 7.1 \\
\hline Yenat & 41 & 53.7 & 46.3 & .0 \\
\hline Sekdre & 32 & 71.9 & 18.8 & 9.4 \\
\hline Sako & 37 & 45.9 & 54.1 & .0 \\
\hline Fetta-woju & 30 & 70.0 & 20.0 & 10.0 \\
\hline Libanos & 29 & 69.0 & 17.2 & 13.8 \\
\hline Total & 230 & 57.8 & 36.1 & 6.1 \\
\hline
\end{tabular}

TABLE 7: Response of local people to the trends in number and type of wild animal species over the past five years in the study area.

\begin{tabular}{|c|c|c|c|c|}
\hline \multirow{2}{*}{ Villages } & \multirow{2}{*}{$N$} & \multicolumn{3}{|c|}{ Trends on wildlife numbers in the last 5 years } \\
\hline & & Increased (\%) & Decreased (\%) & No idea $(\%)$ \\
\hline Kelecha & 33 & 42.4 & 51.5 & 6.1 \\
\hline Seriti & 28 & 42.9 & 57.1 & 0.0 \\
\hline Yenat & 41 & 43.9 & 56.1 & 0.0 \\
\hline Sekdre & 32 & 43.8 & 56.2 & 0.0 \\
\hline Sako & 37 & 45.9 & 54.1 & 0.0 \\
\hline Fetta-woju & 30 & 46.7 & 36.7 & 16.7 \\
\hline Libanos & 29 & 34.5 & 44.8 & 20.7 \\
\hline Total & 230 & 43.0 & 51.3 & 5.7 \\
\hline
\end{tabular}

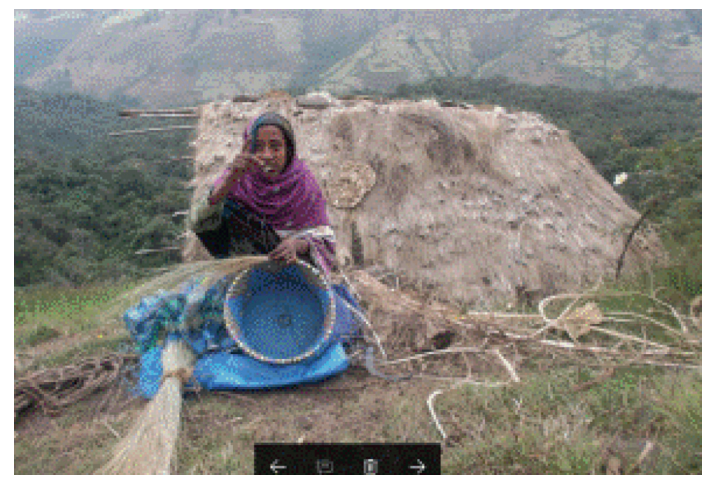

FIGURE 3: A girl guarding cropland against wild animals along with handcrafting in BSNP (photo: Salahadin Merkebu, 2018).

\section{Conclusion}

According to the current result, HWC can have adverse impacts on wildlife and humans alike. There was a strong conflict with local communities and both carnivores and herbivores in and around BSNP. These wild animals potentially caused farmers economic loss especially in villages such as Yenat, Sekdre, Seriti, and Sako. Crop damage, livestock depredation, and human pressure in the park were the main reasons for the cause of HWC in the study area. This HWC may reduce the long-term species conservation support from the community in the area. This in turn has a great negative impact on the conservation of iconic endemic mammal species like gelada and Ethiopian wolf in BSNP. Therefore, it needs urgent measures that can prevent or minimize the risk of conflicts arising between people and animals for the peaceful coexistence of humans and wildlife in the study area. Thus, admitting the impacts of HWC and reducing them is a stepping-stone for ensuring both wildlife conservation and human wellbeing in the study area. In line with this study finding, further study is recommended on the population trends of mammal species to forecast its future population trajectory. Moreover, the government should launch awareness creation on the importance of wildlife and create job opportunities to reduce unemployment in a way to mitigate the pressure of local people on wildlife and the national park.

\section{Data Availability}

The data used are available from the corresponding author upon request.

\section{Conflicts of Interest}

The authors declare no conflicts of interest.

\section{Acknowledgments}

We would like to acknowledge Ethiopian Ministry of Education and Debre Berhan University for funding the study. We would also like to thank the local communities and Borena Sayint National Park managers for all of their support during data collection.

\section{References}

[1] S. I. Ladan, "Examining human wild life conflict in Africa," in Proceeding of International Conference on Biological, Civil and Environmental Engineering (BCEE), pp. 101-105, Dubai, UAE, March 2014.

[2] T. Girmay and Z. Teshome, "Human-wildlife conflict in and around choffa forests, hawzien woreda, eastern Tigray, northern Ethiopia," Implication for Conservation and Conflict Resolution International Journal of Science and Research, vol. 6, no. 3, pp. 1763-1771, 2015.

[3] A. Parasnis, Y. Lele, P. Chourey, and A. Handorein, Mitigating Human-Animal Conflict, Terragreen Press, New Delhi, India, 2014.

[4] A. Berihun, G. Yirga, and G. Tesfaye, "Human-wildlife conflict in kafta-Sheraro national park, Ethiopia world," Journal of Zoology, vol. 3, pp. 154-159, 2016.

[5] A. Acha and M. Temesgen, "Approaches to human-wildlife conflict management in and around Chebera-Churchura national park, southern Ethiopia," Asian Journal of Conservation Biology, vol. 4, pp. 136-142, 2015.

[6] Y. Biru, Z. K. Tessema, and M. Urge, "Perception and attitude of pastoralists on livestock-wildlife interactions around Awash national park, Ethiopia: implication for biodiversity," Conservation Ecological Process, vol. 6, pp. 1-13, 2017.

[7] B. Nibret, M. Yihune, and B. Takele, "Human-wildlife conflict in Choke mountain," Ethiopia International Journal of Biodiversity and Conservation, vol. 9, no. 1, pp. 1-8, 2017.

[8] M. Tweheyo, D. M. Tumusiime, N. Turyahabwe, A. Asiimwe, and L. Orikiriza, "Wildlife damage and control methods around lake Mburo national park," Uganda International Journal of Pest Management, vol. 58, no. 1, pp. 25-31, 2011. 
[9] R. Woodroffe and J. R. Ginsberg, "Edge effects and the extinction of populations inside protected areas," Science, vol. 280, no. 5372, pp. 2126-2128, 1998.

[10] M. Eshete, R. J. Lilieholm, Z. T. Ashenafi, and N. LeaderWilliams, "Community attitudes toward wildlife and protected area in Ethiopia," Society and Natural Resources, vol. 23, pp. 489-506, 2010.

[11] A. E. Amogne, "Development of community based ecotourism in Borena-Saynt national park, north central Ethiopia: opportunities and challenges," Journal of Hospitality Management and Tourism, vol. 5, no. 1, pp. 1-12, 2014.

[12] A. Padpa, Denkoro Proposed National Park Boundary Demarcation Report, Amhara National Regional State Parks Development and Protection Authority Bahir Dar, Ethiopia, Bahir Dar, Ethiopia, 2006.

[13] C. Meseret and Y. Solomon, "Distribution and diversity of small mammals in Borena-Sayint national park, south Wollo, Ethiopia: implications of habitat specialization," International Journal of Biodiversity and Conservation, vol. 6, no. 5, pp. 415-421, 2014.

[14] H. Adal, Z. Asfaw, Z. Woldu, S. Demissew, and P. Van Damme, "An iconic traditional apiculture of park fringe communities of Borena Saynt national park, northeastern Ethiopia," Journal of Ethnobiology and Ethnomedicine, vol. 11, p. 65, 2015.

[15] C. M. Hill, "Conflict of interest between people and baboons: crop raiding in Uganda," International Journal of Primatology, vol. 21, no. 2, pp. 299-315, 2000.

[16] M. Yihune, Human-Wildlife (The Ethiopian Wolf and Gelada Baboon) Conflict in and Around the Simien Mountains National Park Ethiopia, Addis Ababa University, Addis Ababa, Ethiopia, 2006.

[17] L. Naughton-Treves, "Predicting patterns of crop damage by wildlife around Kibale national park, Uganda," Conservation Biology, vol. 12, pp. 156-168, 1998.

[18] E. Andarge, Human-Wildlife Conflict Involving Ethiopian Wolf (Canis Simensis) and Gelada Baboon (Theropithicus Gelada) in and Around Guassa Community Conservation Area, North Shoa, Ethiopia Ethiopia, Addis Ababa University, Addis Ababa, Ethiopia, 2010.

[19] M. Balakrishinan and P. S. Easa, "Habitat preference of large mammals in the parambikulam wildlife sanctuary," India Journal of Conservation Biology, vol. 37, no. 3, pp. 191-200, 1986.

[20] S. Mekonen, "Population status and human conflict of common hippopotamus in Boye Wetland, Jimma, Ethiopia," American Journal of Scientific and Industrial Research, vol. 2, pp. 32-40, 2016.

[21] D. Mojo, J. Rothschuh, and M. Alebachew, "Farmers' perceptions of the impacts of human-wildlife conflict on their livelihood and natural resource management efforts in Cheha Woreda of Guraghe zone, Ethiopia," Ethiopian Institute of Agricultural Research, vol. 8, no. 1, pp. 67-77, 2014.

[22] T. Kumssa and A. Bekele, "Human-wildlife conflict in Senkele Swayne's hartebeest sanctuary, Ethiopia," Journal of Experimental Biology and Agricultural Science, vol. 1, pp. 32-38, 2013.

[23] N. U. Sekhar, "Crop and livestock depredation caused by wild animals in protected areas: the case of sariska tiger reserve, Rajasthan, India," Environmental Conservation, vol. 25, no. 2, pp. 160-171, 1998.

[24] M. Barua, S. A. Bhagwat, and S. Jadhav, "The hidden dimensions of human-wildlife conflict: health impacts, opportunity and transaction costs," Biological Conservation, vol. 157, pp. 309-316, 2013.

[25] S. Bhatia, S. M. Redpath, K. Suryawanshi, and C. Mishra, "Beyond conflict: exploring the spectrum of human-wildlife interactions and their underlying mechanisms," Oryx, vol. 54, no. 5, 2020.

[26] B. Worku, "Human-wildlife conflict with special emphasis on pest primate in and around Gendo Guratirigni forest, Gida Ayana District, Western Ethiopia," Thesis, Addis Ababa University, Addis Ababa, Ethiopia, 2016.

[27] K. Kate, "Possible strategies/practices in reducing wild animal (primate) crop raids in unprotected areas in hoima, district, conducted in two sub-counties in hoima district, Uganda," 2012.

[28] C. M. Hill, "Crop foraging, crop losses, and crop raiding," Annual Review of Anthropology, vol. 47, no. 1, pp. 377-394, 2018.

[29] D. Datiko and A. Bekele, "Conservation challenge: humanherbivore conflict in Chebera Churchura national park, Ethiopia," Pakistan Journal of Biological Sciences, vol. 16, no. 23, pp. 1758-1764, 2013.

[30] A. Mashalla and J. Ringo, "Status of human-wildlife conflicts in mpanga/kipengere game reserve, Tanzania," International Journal of Environment and Bioenergy, vol. 10, p. 1, 2015. 